\title{
Alocação e mitigação dos riscos em parcerias público-privadas no Brasil
}

\author{
Carlos Marcio Campos Lima \\ Tivit \\ Antonio Carlos Coelho \\ Universidade Federal do Ceará (UFC)
}

\begin{abstract}
O objetivo da pesquisa foi efetuar levantamento das condições referentes à distribuição de risco nas formalizações das parcerias público-privadas no Brasil, a partir do marco legal que instituiu tal forma de implantação de equipamentos sociais no Brasil. Foram avaliados, por pesquisa documental, como os fatores de riscos estão sendo alocados e distribuídos em 15 contratos celebrados, buscando determinar como são mitigados os riscos inerentes entre os parceiros públicos e privados. Os contratos apresentam definição expressiva dos riscos envolvidos e de sua responsabilidade pelos parceiros. As evidências sinalizaram que os parceiros privados têm absorvido, formalmente, a maioria dos fatores de riscos elencados; contudo, há expressas medidas de mitigação dos riscos atribuídos nos contratos ao parceiro privado, pela intervenção em última instância do ente público envolvido.
\end{abstract}

Palavras-chave: parcerias público-privadas; alocação e mitigação de riscos; financiamento de obras públicas.

\begin{abstract}
Asignación y mitigación de riesgos en la colaboración público-privada en Brasil
El objetivo de la investigación fue inspeccionar las condiciones en cuanto a la distribución del riesgo en contrataciones por la colaboración público-privada en Brasil, desde que el marco legal estableció tal despliegue de equipamiento social en Brasil. Fueron evaluados, por investigación documental, como los factores de riesgo están siendo asignados y distribuidos en 15 contratos, buscando determinar cómo se mitigan los riesgos entre los socios públicos y privados. Los contratos tienen expresiva definición de los riesgos y su responsabilidad definida para los socios. La evidencia indica que los socios privados formalmente han absorbido la mayoría de los factores de riesgo mencionados; Sin embargo, hay medidas de mitigación de riesgo expreso otorgadas en contratos con el socio privado, por la intervención en última instancia de la entidad pública que se trate.
\end{abstract}

Palabras clave: colaboración público-privada; asignación y mitigación de riesgos; financiación de obras públicas.

DOI: http://dx.doi.org/10.1590/0034-7612130020

(c) BY-NC

Artigo recebido em 3 fev. 2014 e aceito em 22 set. 2014.

Os autores agradecem a colaboração e valiosa contribuição de Allan Pinheiro Holanda. 


\begin{abstract}
Allocating and mitigating risks in public-private partnerships in Brazil
The objective of the research was to survey conditions regarding risk sharing in public-private partnerships contracting in Brazil, from the legal framework establishment that allowed such social equipment deployment in Brazil. It was evaluated through documentary research how the risk factors are being allocated and distributed in 15 contracts, seeking to determine how the risks are mitigated between the public and private partners. The contracts have expressive definition of the risks involved and their liability for the partners. The evidences indicated that private partners have formally absorbed most of the risk factors listed; however, there are express risks' mitigation measures granted in contracts to the private partner, by intervention in last instance of the public entity involved.
\end{abstract}

KEYWORDs: public-private partnerships; risk allocation and mitigation; public works funding.

\title{
1. Introdução
}

A crise nos anos 1980 conduziu o Estado brasileiro a um processo constante de reforma, que culminou com rearranjos na forma de financiamento de atividades cuja realização sempre esteve historicamente atribuída ao Governo. Segundo Nobre (2006:1), "a falência do modelo institucional e de financiamento da infraestrutura, centralizado no Estado, segundo os próprios governantes, foi o principal responsável por esta situação". Como resultado dessa transformação, surge forte tendência para a cessão dos riscos de financiamento da infraestrutura pública, outrora assumidos exclusivamente pelo setor público, para o setor privado.

Dentro desse contexto, no âmbito do Programa Nacional de Desestatização (PND), foram realizadas várias privatizações no Brasil com o objetivo de aprimorar a infraestrutura pública por meio de política permanente de investimentos patrocinada pelo setor privado. Além da transferência total e por período indeterminado de atividades e serviços públicos, o PND também trouxe em seu arcabouço jurídico o regime jurídico de concessões e permissões de serviços públicos, "a concessão comum", normatizada pela Lei Geral das Concessões do Serviço Público (Lei oㅗ 8.987/1995).

Em período mais recente, surge a parceria público-privada como novo incentivo ao ingresso de capitais privados no financiamento do setor de infraestrutura. A proposta da parceria público-privada é dinamizar alguns aspectos dessa lei que trata de forma mais genérica da concessão de serviços públicos.

A rigor, a entrada de capitais privados no financiamento e na operação de equipamentos de infraestrutura estaria condicionada tão somente à baixa disponibilidade de recursos orçamentários, mercê da imensa demanda por infraestrutura no país e da impossibilidade política de emissão de novos impostos, pois somente nessa condição os investimentos poderiam continuar a ser geridos diretamente pela máquina governamental.

A atração dos capitais privados, que buscam remuneração adequada aos riscos associados à atividade a ser financiada, dependeria muito mais do grau de risco assumido pelo ente 
oficial, uma vez que os empreendimentos estariam associados a atividades de serviços, cuja utilização pode se dar de forma aleatória e incerta.

O tema, associando assunção de risco e efetividade de captação de recursos privados no financiamento de obras e serviços públicos, já foi abordado internacionalmente, seja do ponto de vista analítico, seja por evidências de sua aplicação (Grimsey e Lewis, 2002; Thomson, 2005; Torrijos, 2006; Pérez, 2011).

A proposta de alocar de forma objetiva os fatores de riscos associados à construção e ao funcionamento de equipamentos públicos entre o setor estatal e o setor privado no Brasil, buscando mitigar tais fatores de riscos, antes eminentemente estatais, por seu repasse compartilhado à iniciativa privada e por meio de novas possibilidades de associação entre os dois setores, surge com o advento da Lei no 11.079/2004 (Lei das Parcerias Público-Privadas), que tem a intenção de criar ambiente de negócios mais seguro para o aporte de capitais da iniciativa privada ao financiamento de infraestrutura.

Desde então, e a partir desse marco regulatório, identificaram-se 22 projetos de investimento em infraestrutura — até o termo da pesquisa, junho de 2010 — nas mais diversas áreas de equipamentos urbanos, dos quais se teve acesso, por disponibilização, aos contratos de 15 de tais projetos.

A questão que se busca entender diz respeito a captar, por meio de evidências, de que forma tais contratos abordam a distribuição de riscos específicos — do financiamento em si; de aspectos macroeconômicos; da operação; da construção; e do funcionamento - entre os parceiros públicos e privados.

Assim, tem-se como objetivo da pesquisa levantar os termos contratuais de alocação e de responsabilidade por riscos, examinando como se alocaram, na expectativa de que sejam mitigados os riscos nos contratos realizados no Brasil baseados em parcerias público-privadas.

Vale destacar que não se localizaram estudos empíricos abordando a interação risco e contratos de parcerias público-privadas no Brasil, o que se pode explicar pela inserção recente de tal concessão patrocinada, já que apenas em 2004 foi instituído o marco legal dessas parcerias público-privadas no Brasil. Tal constatação funciona mesmo como justificativa para a pesquisa, que assume, assim, caráter exploratório.

\section{Revisão da literatura}

O Estado sempre teve papel de protagonista na sociedade moderna, fomentando ao longo da sua relação com a política e a economia o desenvolvimento econômico das nações. Assumindo seu caráter intervencionista, o erário público também foi direcionado para a provisão de bens e serviços, ditos públicos, na premissa de que tais serviços não seriam fornecidos de forma adequada pelo sistema de mercado. Conforme explica Pego Filho, Candido Júnior e Pereira (1999:6):

(...) a teoria de finanças públicas prevê alguns casos clássicos de intervenção governamental: $i$ ) nos setores em que a discriminação de preços e a cobrança de tarifas são difíceis, devido à inca- 
pacidade de exclusão do consumo; ii) nos monopólios naturais, nas quais, em geral, o Estado é o candidato mais indicado a assumir; iii) nos oligopólios que tenham necessidade de uma escala de produção em grandes proporções que viabilize o negócio; $i v)$ no caso de externalidades positivas, nas quais, em geral, a iniciativa privada, a partir de uma perspectiva macroeconômica, não gera produção suficiente; e $v$ ) nos setores em que há riscos e incertezas na provisão de bens que tenham grande relevância no processo de desenvolvimento econômico. Nessa situação, cabe ao governo identificar esses setores e atuar diretamente ou incentivar a provisão desses bens e/ ou serviços.

A importância do Estado na provisão dos serviços de ampliação da infraestrutura vem, de outra parte, ao encontro das necessidades econômicas tanto do setor público quanto do setor privado em suas atividades próprias. Segundo Pena (2008:11), “(...) a infraestrutura é de grande importância para a estratégia de desenvolvimento da maioria dos países, tendo implicações tanto na redução do custo quanto na eficiência do sistema econômico como um todo".

No entanto, o padrão estatal de financiamento, seja pela administração direta ou indireta, demonstrou limitações quando considerado como fonte exclusiva de recursos para o desenvolvimento da infraestrutura. No caso da administração direta a modalidade de financiamento, através do endividamento direto dos estados na realização de operações de crédito, sofreu grandes restrições que acabaram por ensejar uma crise de endividamento, restringindo essa modalidade de financiamento da infraestrutura no Brasil. Conforme Maia e Saraiva (2012:131):

Por conta desses "descalabros" nas dívidas estaduais, o governo brasileiro, a partir da Constituição de 1934, suspendeu a descentralização fiscal imperante na República Velha, instituindo novo sistema tributário e de repartição de receitas, retirando dos estados os direitos de taxarem seus produtos de exportação e de contrair livremente empréstimos no exterior.

No caso da administração indireta o uso político das empresas estatais provocou a perda de foco na ampliação e modernização da infraestrutura em função de políticas econômicas de curto prazo como a de controle da inflação. Conforme Pego Filho, Candido Júnior e Pereira (1999:31) "de 1979 a 1985, com exceção dos preços dos derivados de petróleo, todas as tarifas foram reajustadas abaixo da inflação e reduzidas, em média, 40\% em termos reais”.

Dessa forma, com as limitações de financiamento do Estado de forma mais incisiva, no governo Collor foi adotado um amplo programa de desestatizações visando à redução do Estado (Ferreira e Malliagros, 1999). Surge então a Medida Provisória no 155 , depois transformada na Lei no 8.031, instituindo o Programa Nacional de Desestatização (PND).

Em linhas gerais, o objetivo do PND foi atrair a iniciativa privada para o financiamento de atividades econômicas anteriormente exploradas pelo setor público. Conforme Nunes (1998:208), tal instituto “(...) permitiu a transferência da responsabilidade por investimentos que o ente governamental não teria condições de realizar, o que tende a intensificar avanços tecnológicos e elevar a eficiência sistêmica". 
Vale destacar que, mesmo em meio ao quadro débil das empresas estatais, a transferência para a iniciativa privada do papel de financiador da infraestrutura pública trouxe resultados significativos, em vários aspectos, se comparada com o cenário anterior. A eficiência praticamente dobrou quando medida em termos de vendas por empregado, aumentando em $83 \%$ a produtividade da mão de obra. A lucratividade passou de negativa para positiva, o patrimônio líquido dos acionistas aumentou quase cinco vezes, enquanto a dívida diminuía e a liquidez aumentava. O investimento médio também quase quintuplicou, aumentando mais de quatro vezes como proporção das vendas e mais do que o dobro em relação aos ativos fixos.

Focando o desempenho pelo total das empresas privatizadas, constatou-se que as vendas por empregado aumentaram em 92\% delas; o lucro líquido aumentou em 78\% das privatizadas; os investimentos tiveram incremento noutras $93 \%$ das entidades e a produtividade da mão de obra cresceu em todas elas (Pinheiro, 2000).

Mesmo com o esforço do setor público em transferir para o setor privado parte da responsabilidade de financiamento da infraestrutura, vale destacar que as privatizações não se tornaram uma solução intermitente para o problema. Conforme explicam Albuquerque, Rebelatto e Savi (2009:2): “(...) mesmo que tenham gerado efeitos positivos, são recursos finitos. Deste modo, essa foi uma alternativa que apresentou prazo determinado para sua conclusão e, portanto, não ofereceu argumentos fortes para o incremento continuado".

Cabe ainda destacar que o esgotamento do processo de privatizações foi impulsionado pela reduzida experiência do Estado em regulação, como também em virtude de um desapontamento quanto ao número reduzido e ineficiente dos canais de financiamentos privados no Brasil. A preponderância do financiamento estatal da atividade econômica nacional implicou que grande parte das firmas privatizadas dependessem, em última instância, dos bancos estatais (Coelho e Martins, 2006). Neste mesmo sentido afirma Reis (2008:13):

O processo de privatizações, embora tenha sido proposto como uma solução para os baixos níveis de investimentos em infraestrutura acabou por não resolver o problema, uma vez que o setor privado se mostrou incapaz, diante da regulação vigente (com exceção das telecomunicações), de passar a financiar os volumes de recursos necessários para a expansão da infraestrutura e, assim, eliminar os gargalos que impedem o crescimento econômico e o escoamento mais rápido da produção industrial e agrícola no Brasil.

Outra modalidade de concessão de serviços públicos para a iniciativa privada, advinda do arcabouço jurídico do Plano Nacional das Desestatizações (PND) (Lei nํ 8.031), foram as concessões comuns. A concessão de serviços públicos, diferentemente da venda direta de ativos, não suprime o controle do Estado. Nesse modelo, a administração pública passa a determinar as regras gerais, enquanto a produção de serviços fica a cargo da iniciativa privada (empresa que recebeu a concessão do serviço público).

Dessa forma, a transferência de atividades produtivas, historicamente desempenhadas pelo Estado, permitiu, no caso brasileiro, que a iniciativa privada fosse direcionada para o financiamento e a operação de atividades nas quais é especialista, trazendo assim, provavel- 
mente, maior nível de produtividade. Segundo Matos Filho e Oliveira (1996:18), "a concessão traz alguns efeitos indiretos, uma vez que a iniciativa privada tem maior flexibilidade na gestão de seus empreendimentos e um nível de eficiência interna muito mais elevado".

Com isso entende-se que, de forma geral, o risco do negócio seja absorvido pelo ente privado e está associado à geração de receita, que por sua vez é impactada diretamente pela oscilação de demanda (Nobre, 2006). Vale destacar que a receita do ente privado tem relação direta com o modelo de tarifação do usuário final, que por sua vez deve ser aderente à legislação pertinente; no caso, a Lei no 8.987/1995. De acordo com Harb (2012:66):

(...) a lei fixa um princípio segundo o qual não podem os usuários ser onerados excessivamente pela cobrança de tarifas, que nas concessões comuns de serviço público em geral consistem no principal ou exclusivo elemento de remuneração do concessionário, diferentemente dos demais contratos administrativos comuns, onde a remuneração é arcada pela Administração Pública.

Aconteceu que, mesmo com as concessões comuns, a expectativa do governo, no que tange ao montante de investimentos previstos, para o setor de infraestrutura foi frustrada. $\mathrm{O}$ pequeno interesse do setor privado nas concessões foi explicado pela falta de marco regulatório claro que tratasse de controvérsias sobre titularidade, competência regulatória, responsabilidades e obrigações dos prestadores de serviços, prioridades de atendimento e padrões de qualidade (Reis, 2008). Tal omissão aumentava substancialmente a incerteza com que se defrontava a concessionária, sem flexibilidade de ajustes tempestivos para mitigar tal risco.

Com isso, a Lei das Concessões Comuns foi complementada e atualizada a partir da Lei no 11.079/2004. Segundo Loureiro (2007:73): “A Lei 11.079/04 é uma lei que se soma às Leis 8.666/93 e 8.987/95, visando à prestação de serviços públicos mais eficientes". A principal novidade junto a essa legislação foi o advento de nova modalidade de concessão denominada patrocinada. Segundo Amaral (2002:38): “A partir da edição da 11.079, de 30.12.2004, passaram a existir dois: assim apelidada 'concessão comum', ou seja, a já existente, e a 'concessão patrocinada', criada pela nova lei como um dos dois tipos de parceria público-privada”.

A concessão patrocinada por excelência passa a ser parcerias público-privadas, as quais surgem como nova alternativa a ser utilizada pelo governo para a realização de investimentos em infraestrtutura, em contexto de forte ajuste fiscal.

Conforme explica Franco (2007:153): “argumenta-se que as parcerias público-privadas podem gerar uma melhora do quadro fiscal, por meio de projetos mais baratos, o que, de fato tem fundamento".

Com relação aos riscos, o principal enfoque dado pelo novo diploma legal foi que a responsabilidade por eles ficasse restrita à repartição objetiva dos riscos entre os parceiros. Segundo Zamchim (2012:147), "quem exibe maior poder em determinado aspecto do empreendimento torna-se mais responsável por eventuais ocorrências aleatórias daí decorrentes".

Além da alocação dos fatores de riscos, a legislação em causa ainda trouxe salvaguardas que mitigariam alguns dos fatores de risco possíveis. O processo de mitigação destes fatores de riscos envolve ações que busquem reduzir a probabilidade de ocorrência de eventos adver- 
sos ao bom termo do projeto ou, em caso da iminência de fatos inesperados, de definições da absorção do impacto que eles possam produzir.

Os contratos realizados em regime de parceria público-privada devem possuir um pacote de garantias e de formas de mitigação de riscos composto por várias obrigações em favor dos agentes financiadores a serem assumidas pela concessionária ou pelos sócios privados (Borges e Neves, 2005). Esta premissa é um dos mecanismos para a atração da iniciativa privada ao financiamento da infraestrutura pública. Segundo França (2007:113):

A falta de confiança e de credibilidade do poder público, extraída de experiências negativas anteriores, relativas à quebra de regras contratuais, especialmente em projetos de longo prazo foi o mais relevante aspecto considerado para a implantação desse modelo de contratação no Brasil.

Do ponto de vista conceitual, os riscos podem ser absorvidos por dois atores na contratação de tais parcerias, segundo Grimsey e Lewis (2002), quais sejam: a entidade governamental legalmente responsável pela prestação do serviço; o patrocinador do projeto, o qual pode desenvolver o projeto por meio de Sociedades de Propósito Específico e que é responsável pelo levantamento de recursos, pela implementação da obra e pela gestão do empreendimento. Identificaram tais autores que nove tipos diferentes de fatores de risco podem impactar os resultados de projetos empreendidos por meio de parcerias público-privadas:

、 Risco Técnico, relativo a falhas de engenharia e de design;

v Risco de Construção, que inclui erros na construção, inadequadas técnicas de construção e/ ou falhas em materiais de construção;

v Risco Operacional, associado a custos de operação e de manutenção se apresentarem mais elevados do que o planejado;

v Risco de Receita (Demanda), oriundo da possibilidade de demanda insuficiente ou abaixo do previsto;

v Risco Financeiro, o qual trata de erros na estimativa dos fluxos de receitas do projeto e dos custos de financiamento do projeto;

、 Risco de Força Maior, envolvendo eventos extraordinários, como guerras ou calamidades;

v Risco Regulatório/Político, decorrente de mudanças de governo e/ou de políticas públicas, com consequente alterações em leis e regulamentos aplicáveis às operações de PPP;

- Risco Ambiental, derivado do impacto negativo do projeto sobre o meio ambiente; e

v Risco de Default, que significa o fracasso total do projeto, que, geralmente, estaria associado a uma combinação dos eventos elencados individualmente acima.

Em outra perspectiva, Torrijos (2006) identificou, associada a fatores de risco declarados, série de medidas e providências que poderiam contribuir para mitigar riscos comuns às parcerias público-privadas: 
- Risco de Sobrepreço ou Superfaturamento: estabelecer preços fixos no contrato;

- Risco de Atraso na entrega do serviço: estabelecer contratualmente tempo limitado para a construção do bem objeto da parceria;

V Risco de Desapropriações: estabelecer contrato de concessão entre as partes;

v Risco de Demanda: contratar estudos com projeções confiáveis da demanda futura;

- Risco de Operação e Manutenção: estabelecer contratualmente responsabilidades expressas com tais gastos;

v Risco de Câmbio: estabelecer contratos de financiamento na mesma moeda dos futuros recebimentos; e

Risco de Acidentes: contratar seguros apropriados.

Thomson (2005) investigou a presença explícita de menção de risco em 10 parcerias público-privadas financiadas pelo Banco Europeu de Investimento. Identificaram-se como principais riscos para as parcerias em tela: decorrentes dos contratos de financiamento; oriundos de falhas no prazo de conclusão das obras; de gastos superiores aos do orçamento previsto; de funcionamento ou de manutenção das obras e serviços estipulados; além de riscos de rescisão da parceria e de alterações em remunerações estipuladas.

A distribuição de risco em parcerias público-privadas foi estudada por Pérez (2011), analisando o cenário espanhol; identificou que as parcerias concretizadas entre o Administrador de Infraestructuras Ferroviárias (Adif) e empresas privadas adotam mecanismos de redução de riscos decorrentes de sobrepreço ou superfaturamento nas desapropriações e na ausência de condições de financiamento. Para tais casos, a Adif assume os custos integrais das expropriações e assume, ainda, 40\% dos custos das construções ferroviárias.

\section{Metodologia}

Quanto à abordagem da pesquisa adotada, o trabalho classifica-se como estudo qualitativo. O método qualitativo representa, em princípio, a intenção de garantir a precisão dos resultados, evitar distorções de análise e interpretação, possibilitando, consequentemente, uma margem de segurança quanto às inferências (Richardson, 2008).

O estudo que produziu a pesquisa teve escopo inicialmente exploratório. Segundo Silva (2003:65), "A pesquisa é dada como exploratória, onde há pouco conhecimento acumulado e sistematizado".

Quanto aos meios, a pesquisa se caracteriza como documental. Segundo Martins (2008:55), "A estratégia de pesquisa documental é característica dos estudos que utilizam documentos como fonte de dados, informações e evidências". Os documentos utilizados nesta pesquisa foram os contratos utilizados para celebrar as parcerias público-privadas no Brasil. A 
utilização desse instrumento legal entende-se compatível com a expectativa de capturar como o agente público e o agente privado estão pactuando a identificação, a alocação e a mitigação dos fatores de riscos nos projetos de construção e operação de obras públicas, por meio das parcerias público-privadas.

Para a análise proposta, foram coletados os dados de 15 contratos celebrados entre o início do ano de 2004 (marco legal das parcerias público-privadas) e junho de 2010 (termo da pesquisa) a partir de consulta ao endereço eletrônico do Ministério do Planejamento (<www. planejamento.gov.br/hotsites/ppp/index.htm>). A análise dos contratos se deu pela técnica de análise de conteúdo, com a absorção e categorização das cláusulas contratuais referidas a gestão do risco do projeto. Tal técnica permite que se separem os conceitos que interessam ao estudo, por critérios de contagem, catalogação ou categorização (Bardin, 2011).

Os contratos, objeto da pesquisa, representam $68 \%$ do universo de 22 projetos que se tornaram realidade no período estudado. Relacionam-se no quadro 1 os contratos cujo teor foi apreciado e analisado; a crítica foi efetivada pela aplicação dos procedimentos em seguida expendidos, em processo de três etapas.

\begin{tabular}{|c|c|}
\hline Item & Projeto \\
\hline 1 & Estádio Castelão \\
\hline 2 & Sistema de Disposição Oceânica do Jaguaribe \\
\hline 3 & Estádio da Fonte Nova \\
\hline 4 & Hospital Subúrbio \\
\hline 5 & MG-050 \\
\hline 6 & Sistema Penal em MG \\
\hline 7 & Unidade Integrada de Atendimento (UIA) \\
\hline 8 & Novo Mineirão \\
\hline 9 & Ponte e Acesso Rodoviário à Praia do Paiva \\
\hline 10 & Centro Integrado de Ressocialização de Itaquitinga \\
\hline 11 & Cidade da Copa 2014 \\
\hline 12 & Linha 4 do Metrô \\
\hline 13 & Sistema Produtor Alto Tietê \\
\hline 14 & Linha 8 da CPTM \\
\hline 15 & Centro Administrativo do Distrito Federal \\
\hline
\end{tabular}

Fonte: Dados da pesquisa (2013). 
- $1^{\underline{a}}$ Etapa - caracterização dos projetos

Nesta etapa os projetos amostrados foram classificados segundo atributos específicos a cada contrato efetivamente celebrado. Obteve-se, assim, panorama dos contratos, a respeito de tipo de concessão e de concorrência, além de dados relacionados com segmentos atendidos, e a prazo, volume e valor dos projetos a serem implantados.

$\checkmark 2^{a}$ Etapa - categorização, identificação e alocação dos riscos

A partir da individualização do nível de risco inerente a cada contrato foram identificados e alocados os fatores de riscos dos projetos amostrados a partir de três categorias: público, privado e partilhado; na inexistência de tal definição o projeto foi considerado de "categoria não localizada". Esta etapa foi alicerçada nos termos expressos no capítulo II, art. 5o, da Lei no $11.079 / 2004$, onde se estatui que nos contratos em parcerias público-privadas os fatores de riscos devem ser alocados de forma objetiva. Para a catalogação foi utilizada a matriz de riscos definida na figura 1 e baseada em pesquisas similares internacionais e no material de regulamentação do assunto no Brasil.

Figura 1

Matriz de riscos

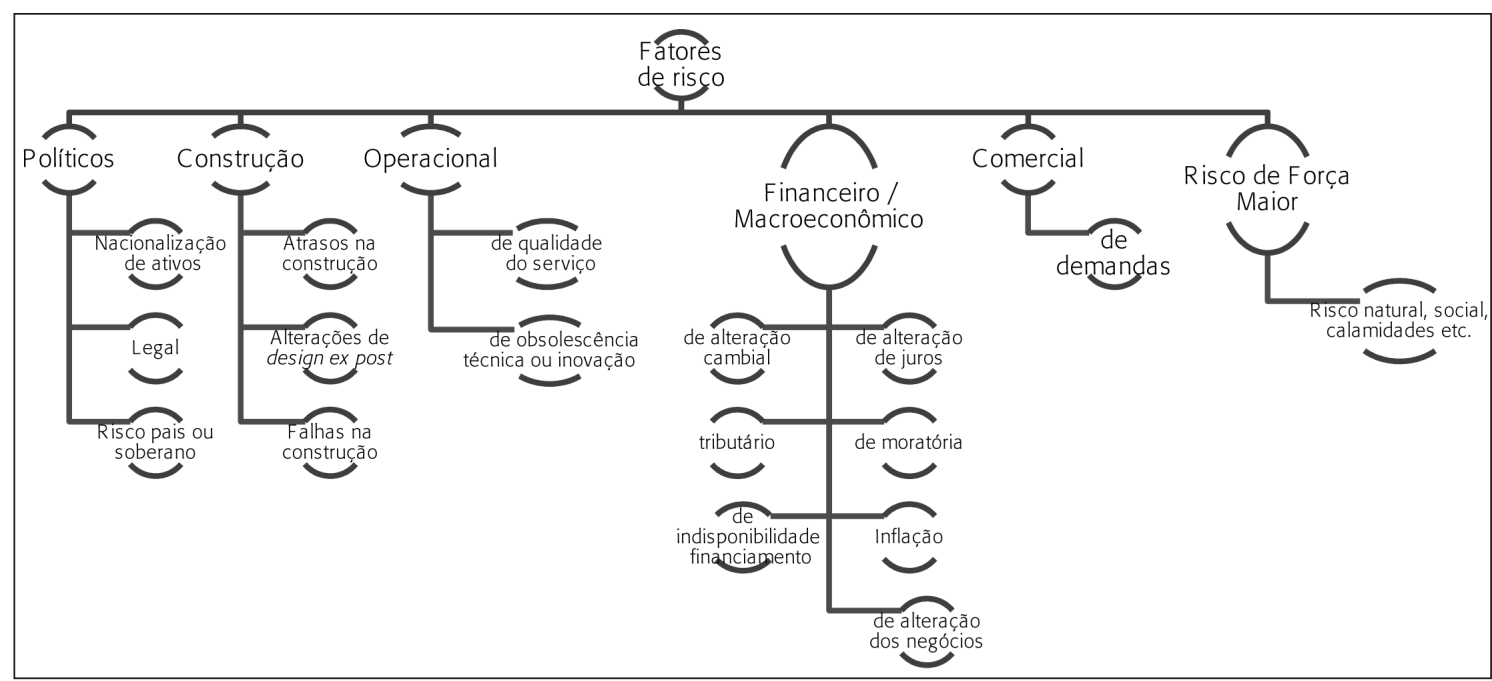

Fontes: Adaptada de Borges e Neves (2005); Bing, Akintoye e Edwards (2005 apud Franco, 2007) e Grimsey e Lewis (2002).

\section{$\checkmark 3^{a}$ Etapa - medidas de mitigação de riscos}

Com fatores de riscos identificados e estabelecida sua alocação, relacionaram-se riscos e medidas de mitigação, consoante expresso nos respectivos contratos, de modo a estabelecer o arcabouço da efetiva alocação e mitigação de riscos entre os parceiros públicos e privados. 
- Resultados

\subsection{Perfil de parcerias público-privadas (PPP) no Brasil}

A crítica do perfil dos contratos de PPP sob análise permite um maior entendimento sobre a complexidade dos projetos abrangidos no período da pesquisa. Pode-se mesmo especular que os fatores de riscos expostos nos tópicos seguintes, no que diz respeito à sua identificação, alocação e mitigação, derivam dessa complexidade.

Constatou-se que em pelo menos $60 \%$ dos contratos pesquisados a opção mais adequada na perspectiva do setor público foi permitir que empresas estrangeiras participassem do certame por meio da modalidade concorrência internacional; tal inferência apoia-se no que mostra o gráfico 1; os demais $40 \%$ foram escolhidos por meio de concorrência onde apenas empresas brasileiras puderam ser convocadas na licitação.

O gráfico 2 mostra os segmentos de infraestrutura cobertos pelos contratos estudados; aí se revelou grande dispersão nas escolhas, já que foram identificados pelo menos oito segmentos dentre 15 contratos examinados; estádios de futebol, associados à Copa do Mundo; centros administrativos; complexos prisionais, saneamento básico e infraestrutura hospitalar, itens de forte carência em nossa infraestrutura; instalações metroviárias e rodoviárias; além de infraestrutura de abastecimento de água, denotando forte carência de serviços diretamente associados à população e que podem possuir atrativos de rentabilidade e baixo risco, em face da baixa oferta histórica de maioria dos itens.

\section{Gráfico 1}

Tipos de concorrência no processo licitatório

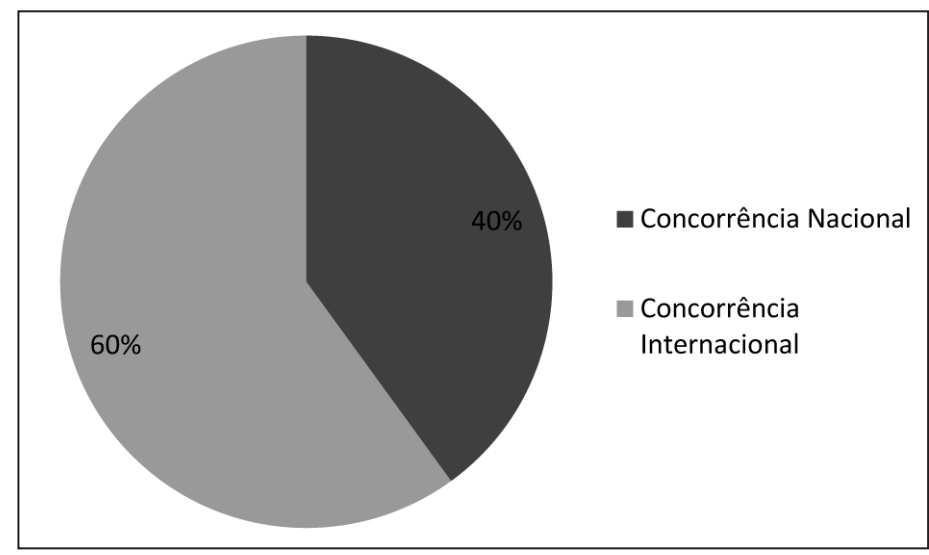

Fonte: Dados da pesquisa (2013).

Os projetos supracitados são historicamente atribuídos à iniciativa pública, seja devido ao seu papel na promoção do desenvolvimento, seja pelo nível de complexidade dos projetos, em geral de longa maturação e onerosos em sua construção. 
ráfico 2

\section{Projetos PPP por segmento de infraestrutura}

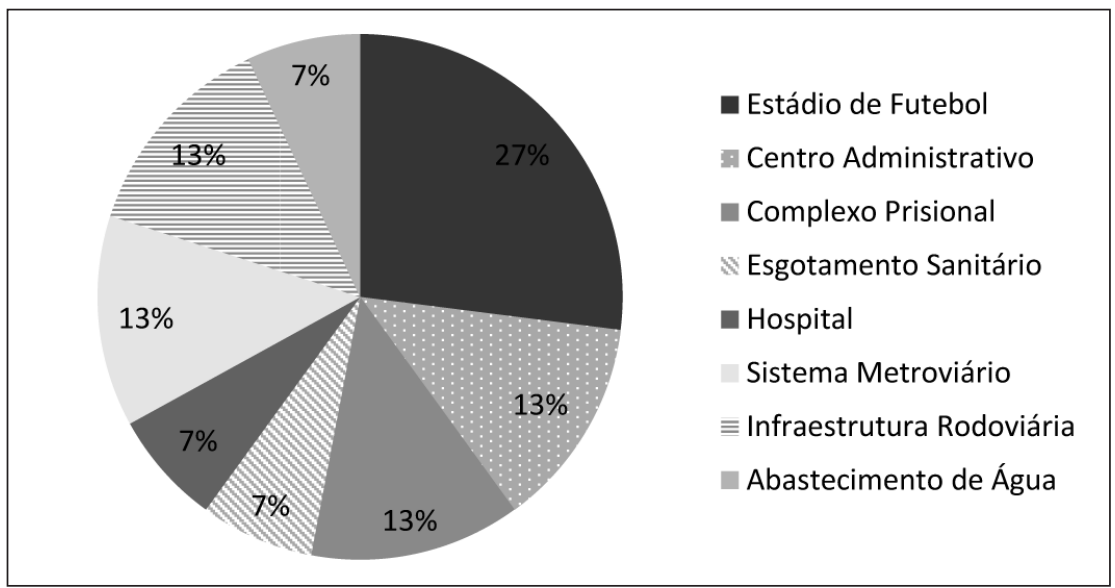

Fonte: Dados da pesquisa (2013).

A distribuição dos contratos, quanto ao prazo de concessão, conforme o gráfico 3, permite-nos perceber a dimensão de longo prazo, característica que levaria a PPP como forma apropriada para gerenciar riscos associados ao retorno demorado de capitais aí investidos. Percebe-se que a maior parte das PPPs estabeleceu termo acima de 20 anos, como vigência contratual. Trata-se de prazos não usuais em nossa relação institucional com o governo, cuja dívida pública é carregada, refinanciada, a cada dia útil.

Gráfico 3

Prazo das concessões objeto de parcerias público-privadas

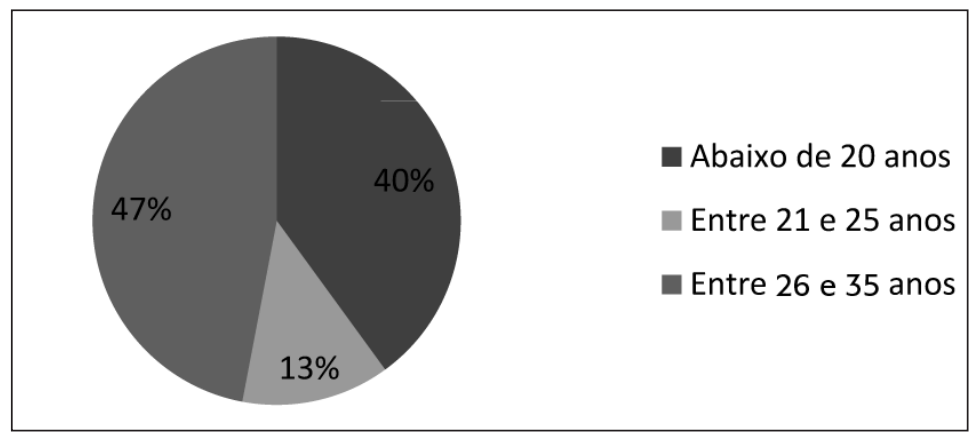

Fonte: Dados da pesquisa (2013).

Com relação ao montante de capital previsto para os contratos, $47 \%$ dos projetos tiveram como objeto do contrato investimentos que variaram entre R\$ 500 milhões e R\$ 1 bilhão, com valores mínimos de R 100 milhões e valores máximos acima de R $\$ 2$ bilhões. 
O montante total, nesse estágio, contudo, ainda é reduzido em face do PIB brasileiro e da necessidade de infraestrutura. Dada a pequena quantidade de projetos, pode-se arguir que essa forma de concessão patrocinada ainda é embrionária em nossa realidade. Isto, de certa forma, pode traduzir a percepção de grande risco que a iniciativa privada tem deste tipo de contrato. No gráfico 4 fica demonstrado o volume dos investimentos realizados no Brasil por intervalo de valores.

$$
\text { Gráfico } 4
$$

\section{Valor dos contratos dos projetos realizados em parcerias público-privadas no Brasil}

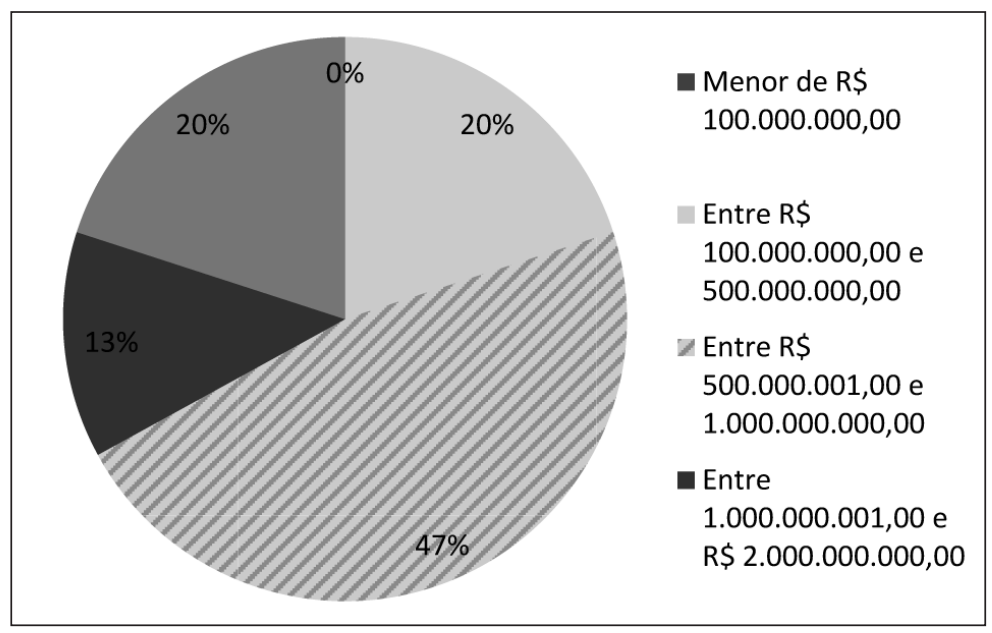

Fonte: Dados da pesquisa (2013).

Os contratos e minutas de contratos estudados revelaram que 80\% dos projetos realizados no Brasil adotaram a concessão administrativa como modelo de parceria público-privada, como se observa no gráfico 5 .

Tal concessão administrativa é realizada quando não é possível ou não é conveniente cobrar do usuário pelo serviço de interesse público prestado pelo parceiro privado. Nessa condição, a receita do parceiro privado é advinda da contraprestação pecuniária fornecida pelo parceiro público. Cruzando-se tal informação com os dados constantes do gráfico 2, fica claro que apenas estádios de futebol teriam condições mercadológicas, no desenho econômicoinstitucional brasileiro, de funcionar com preços ditados pelos consumidores.

Os demais segmentos, mesmo que não dependam diretamente de pagamento direto pelos governos, sofrem restrições de tarifação ditada pelos estamentos governamentais, os quais oscilam em torno de mudanças constantes de políticas públicas. Também aqui se visualiza forte fator de risco para os entes privados da parceria. 


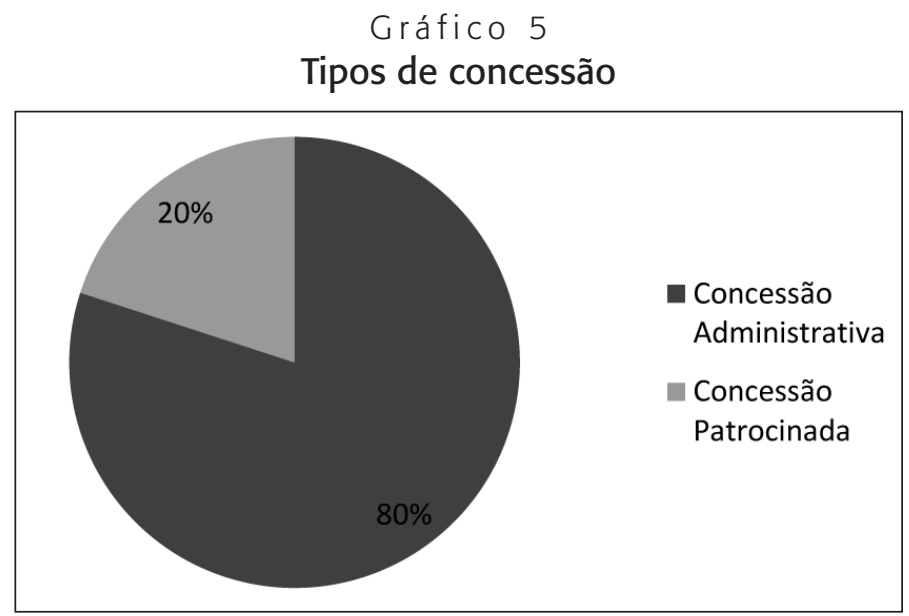

Fonte: Dados da pesquisa (2013).

Característica comum a todos os contratos examinados é a esfera governamental convenente, que é a estadual. Não foram identificados projetos em nível federal, o que corrobora o caráter embrionário de tal arranjo contratual.

Ademais, pelo gráfico 6, observou-se a distribuição geográfica dos projetos; as regiões em que mais se buscaram a parceria público-privada são aquelas de maior pressão demográfica e de maior integração econômica; a concentração de projetos adotando esta política de financiamento está na região Sudeste, seguida pela região Nordeste, com 47\% e 46\% dos projetos, respectivamente. As regiões Norte e Sul, certamente por motivos diferentes, não optaram por parcerias público-privadas.

Parcerias público-privadas por região geográfica

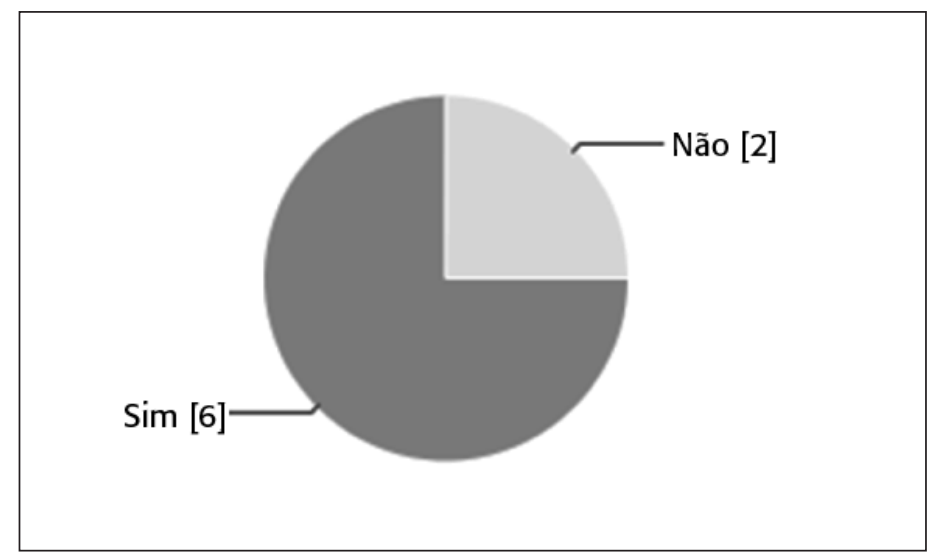

Fonte: Dados da pesquisa (2013). 


\subsection{Alocação de fatores de risco nos contratos PPP}

Os fatores de risco tratados expressamente nos contratos pesquisados excedem aqueles apontados na literatura internacional (Grimsey e Lewis, 2002; Pérez, 2011) e totalizaram 17 tipos diferentes de fatores de risco, conforme se nota na tabela 1 . Contudo, tais fatores estão agrupados normativamente em seis grupos, que se assemelham àqueles vistos na literatura.

De início, constata-se que não foi encontrada alocação objetiva para os fatores de risco referentes aos riscos: soberano, de nacionalização e de moratória, embora expressos na literatura especializada. As alocações de responsabilidade foram distribuídas pela análise de conteúdo entre as categorias: pública, privada e partilhada.

Verificou-se que, na categoria de riscos políticos, os fatores de risco soberano e de nacionalização dos ativos não foram sequer mencionados, portanto não alocados nos 15 contratos avaliados, apesar de haver predominância de concorrência internacional, conforme se visualiza na tabela 1.

Tabela 1

Alocação contratual dos fatores de risco

\begin{tabular}{|c|c|c|c|c|c|c|}
\hline \multirow[b]{2}{*}{ Item } & \multirow[b]{2}{*}{ Tipo de Risco } & \multirow[b]{2}{*}{ Fator de Risco } & \multicolumn{4}{|c|}{ Tipo de Alocação (em percentagem) } \\
\hline & & & Privado & Público & Partilhado & $\begin{array}{c}\text { Não } \\
\text { Localizado }\end{array}$ \\
\hline 1 & \multirow{3}{*}{ Político } & País ou soberano & $0 \%$ & $0 \%$ & $0 \%$ & $100 \%$ \\
\hline 2 & & De nacionalização de ativos & $0 \%$ & $0 \%$ & $0 \%$ & $100 \%$ \\
\hline 3 & & Legal & $0 \%$ & $100 \%$ & $0 \%$ & $0 \%$ \\
\hline 4 & $\begin{array}{c}\text { Força Maior ou Caso } \\
\text { Fortuito }\end{array}$ & Natural, social, calamidades etc. & $0 \%$ & $0 \%$ & $93 \%$ & $7 \%$ \\
\hline 5 & \multirow{3}{*}{ Construção } & Atrasos na construção & $67 \%$ & $0 \%$ & $0 \%$ & $33 \%$ \\
\hline 6 & & Alterações de design ex post & $0 \%$ & $87 \%$ & $0 \%$ & $13 \%$ \\
\hline 7 & & Falhas na construção & $73 \%$ & $0 \%$ & $0 \%$ & $27 \%$ \\
\hline 8 & \multirow{7}{*}{$\begin{array}{c}\text { Financeiro ou Macroe- } \\
\text { conômico }\end{array}$} & De alteração dos custos & $100 \%$ & $0 \%$ & $0 \%$ & $0 \%$ \\
\hline 9 & & De aumento da carga tributária & $0 \%$ & $93 \%$ & $0 \%$ & $7 \%$ \\
\hline 10 & & De variação cambial & $73 \%$ & $7 \%$ & $0 \%$ & $20 \%$ \\
\hline 11 & & De aumento da taxa de juros & $67 \%$ & $0 \%$ & $0 \%$ & $33 \%$ \\
\hline 12 & & De indisponibilidade de financiamento & $100 \%$ & $0 \%$ & $0 \%$ & $0 \%$ \\
\hline 13 & & De inflação & $7 \%$ & $0 \%$ & $0 \%$ & $93 \%$ \\
\hline 14 & & Moratória & $0 \%$ & $0 \%$ & $0 \%$ & $100 \%$ \\
\hline 15 & \multirow{2}{*}{ Operacional } & De qualidade do serviço & $93 \%$ & $0 \%$ & $0 \%$ & $7 \%$ \\
\hline 16 & & De obsolescência técnica ou inovação & $40 \%$ & $7 \%$ & $0 \%$ & $53 \%$ \\
\hline 17 & De mercado & De demanda & $0 \%$ & $0 \%$ & $53 \%$ & $47 \%$ \\
\hline \multicolumn{3}{|r|}{ TOTAL } & $36 \%$ & $17 \%$ & $9 \%$ & $38 \%$ \\
\hline \multicolumn{3}{|c|}{ TOTAL (255 observações) } & 93 & 44 & 22 & 96 \\
\hline
\end{tabular}

Fonte: Dados da pesquisa (2013).

Obs.: Os percentuais estão sempre calculados sobre os 15 contratos; o total está calculado sobre o total de observações (15*17=255). 
Ainda na categoria riscos políticos observa-se que, quanto ao fator de risco legal, 100\% dos contratos avaliados o alocaram como de responsabilidade do ente público. Nesse caso, o setor público assumiria impacto de aumento de custos, redução de receita ou mudança na qualidade do serviço, decorrentes de mudança na lei ou em atos normativos que afetem a operação da prestação de serviço ou, até mesmo, a continuidade do projeto.

$\mathrm{Na}$ avaliação do fator de risco de caso fortuito ou força maior, conforme a tabela 1, em 93\% dos contratos pesquisados o padrão observado é recorrente e foi atribuído aos setores públicos e privado, através de partilha, esse fator de risco. Na avaliação dos contratos observase que os critérios para o partilhamento dos riscos são: a natureza, a capacidade de absorção e a incapacidade de cumprir o contrato pré ou pós-conclusão.

Nos demais 7\% dos contratos esse fator de risco não foi explicitado. É o caso do contrato de concessão administrativa 6651/06, realizado entre a Sabesp - Companhia de Saneamento Básico do Estado de São Paulo (Parceiro Público) e o Sistema Produtor Alto Tietê S.A. (Parceiro Privado).

Com relação aos fatores de risco atribuídos à categoria construção verificou-se que o fator de risco atraso na construção foi mencionado em $67 \%$ dos 15 contratos avaliados como um risco a ser alocado ao parceiro privado; nos outros 33\% esse risco não foi identificado no projeto, seja porque não foi mencionado ou porque não fazia parte da natureza do projeto. $\mathrm{O}$ risco de falhas na construção seguiu uma distribuição percentual parecida, sendo alocado ao parceiro privado em $73 \%$ das vezes. Em $27 \%$ dos casos, assim como o risco de atraso na construção, esse fator de risco não foi mencionado. Para os casos supracitados, a evidência para a alocação destes fatores de risco ao setor privado é que, em caso de divergências de escopo e prazo, multas e indenizações foram previstas em conformidade com os limites do contrato e eventuais falhas construtivas podem ensejar o abatimento nos pagamentos devido ao parceiro privado. Esse padrão tem sido comum nos contratos estudados nesta pesquisa.

A tabela 1 também mostrou, associado à categoria construção, o fator de risco de alteração de design ex post. Em 87\% dos contratos avaliados esse fator de risco foi alocado ao setor público; nos outros $13 \%$ dos contratos esse fator de risco não foi localizado. A cláusula contratual que trata do assunto traz em si um padrão textual recorrente nos contratos, que denota como os riscos de construção estão intimamente ligados ao projeto do empreendimento, ficando estes sob a responsabilidade do setor público em caso de mudança nas especificações da prestação de serviço após a assinatura do contrato.

Em relação aos fatores de riscos categorizados como financeiros verificou-se que o fator de risco de alteração dos custos incialmente previstos no plano de negócios, decorrentes das projeções econômico-financeiras apresentadas na licitação, foi, em 100\% dos contratos avaliados, um risco alocado ao parceiro privado. As cláusulas contratuais avaliadas deixam claro que eventuais erros ou omissões não serão considerados para efeito do equilíbrio econômico-financeiro, sendo considerado risco exclusivo da contratada a correta avaliação de tais aspectos. Vale destacar que alguns contratos abrandam essa alocação quando a majoração dos custos tem causa no setor público, o que enseja possibilidade de litígios, demandas e lides judiciais sobre a origem de tais possíveis custos. 
$\mathrm{Na}$ avaliação do fator de risco de alteração tributária os contratos possuem cláusulas que se repetem com certa frequência. Alterações nos custos decorrentes de mudanças nas alíquotas dos tributos previstos no plano de negócios (com exceção do imposto sobre a renda) ou da criação de um tributo novo não existente à época da formulação da proposta econômico-financeira em $93 \%$ dos contratos avaliados foram alocadas ao setor público. Em outros $7 \%$ dos contratos esse fator de risco não foi mencionado.

Para o fator de risco de alteração observa-se que em $20 \%$ dos contratos avaliados esse risco não foi identificado, em função mesmo da natureza do empreendimento licitado. Para $73 \%$ dos contratos, riscos associados a variação cambial foram atribuídos ao setor privado. Nos contratos avaliados, as projeções cambiais são assumidas pelo parceiro privado no plano de negócios, como um risco de negócio. Vale destacar que em alguns contratos, onde esse risco é atribuído ao setor privado, há um abrandamento quando a variação cambial é extraordinária e imprevisível, sem que se defina explicitamente a extensão de tais expressões. Para esses casos existe possibilidade de revisão contratual. Em apenas 7\% dos contratos estudados esse risco foi partilhado, com a variação cambial sendo absorvida pelo setor privado até dado limite de variação. Esse foi o caso do projeto da Linha 4 do Metrô de São Paulo.

Em relação ao fator de risco de alteração de juros, 67\% das cláusulas contratuais que trataram desse risco atribuíram ao setor privado a absorção desse risco. Nesse caso, ora os contratos tratam os juros como obrigações assumidas pela contratada em relação à proposta econômica e projeções financeiras, ora como custo de empréstimos e financiamentos assumidos pela concessionária para realização de investimentos ou custeio das operações. Em ambos os casos a visão é de que esse é um risco de mercado. Observa-se também que esse risco não foi mencionado por nenhuma cláusula contratual em 33\% dos projetos avaliados.

Em 100\% dos contratos o fator de risco associado ao financiamento dos empreendimentos foi alocado ao setor privado da parceria. Não se verificou, portanto, modelo tripartite em que o agente financeiro pode carregar parte desse risco específico. As cláusulas contratuais que tratam o assunto afirmam, em formato padrão, que a obtenção, aplicação e gestão da contratação de financiamento para a consecução do objeto do contrato, seja através de instituição financeira, banco de fomento ou agência multilateral de crédito, é uma responsabilidade do concessionário.

Por fim, nessa categoria, a moratória não foi citada como fator de risco, pelo menos de forma explícita, e assim alocada de forma objetiva nos contratos, conforme preconiza o art. 4º $\S^{\circ}{ }^{\circ}$, da Lei no ${ }^{\circ} 11.079 / 2004$. Apesar disso, não há dúvidas sobre o impacto negativo para o parceiro privado, caso as receitas projetadas não se realizem.

Por outro lado, caso haja acréscimo acentuado nos preços de insumos, o que configuraria inflação, com tarifas públicas administradas, notou-se que em apenas $7 \%$ dos contratos a inflação é tratada como uma projeção econômico-financeira e alocada como de inteira responsabilidade do contratado. Nos demais contratos não há menção a tal variável macroeconômica.

Na categoria de risco operacional a qualidade do serviço é fator presente em todos os contratos. Atestou-se que em $93 \%$ dos contratos a concessionária deverá cumprir os critérios, indicadores e parâmetros de qualidade na prestação dos serviços que constam no contrato de concessão. 
Ainda nessa categoria observou-se que, quanto ao fator de obsolescência técnica ou por inovação, em $40 \%$ dos contratos esse fator de risco foi atrelado ao setor privado, com a exigência por parte do setor público de serviços tecnologicamente atualizados. Vale destacar que esse é um quesito a ser avaliado pelo setor público na avaliação de desempenho do contratado.

Ainda assim vale ressalvar que se observa com frequência que essa avaliação pode ser abrandada a depender da inovação tecnológica solicitada pelo contratante, abrindo assim o precedente em última instância para revisão contratual. Esse foi o caso em 7\% dos contratos avaliados nesta pesquisa, que alocou ao setor público a absorção desse fator de risco por meio do aumento da contraprestação pecuniária ao setor privado. Em 53\% dos contratos avaliados não se verificou menção a esse fator de risco.

Na categoria risco de mercado verificou-se que o fator de risco de demanda não foi localizado em $47 \%$ dos contratos. Vale destacar que a natureza dos projetos tem influência nesse resultado, já que em parte relevante dos projetos a demanda é garantida pelo poder público, como é caso dos presídios. Em 53\% dos contratos verificou-se que este fator de risco é partilhado entre o poder público e o poder privado. Nesses casos percebe-se que existem gatilhos bem determinados para a absorção do risco pelo poder privado assim como pelo poder público.

\subsection{Identificação das medidas de mitigação dos fatores de risco}

Na tabela 2 se arrolaram, da análise de conteúdo dos contratos, as medidas (cláusulas contratuais) estabelecidas para mitigar, de diversas maneiras, o risco potencial de default dos empreendimentos alocado para qualquer dos parceiros. Verificaram-se que tais medidas foram estabelecidas 132 vezes nos 15 contratos, consoante se demonstra na tabela já citada.

Na categoria riscos políticos, apenas se considera o risco declarado de alterações legais; observa-se que em $100 \%$ dos contratos foram previstas cláusulas que garantem a aplicação de mecanismos de reequilíbrio econômico financeiro que permitem o acionamento do setor público, protegendo o setor privado quando da ocorrência desses eventos, pela repactuação dos contratos.

Verifica-se ainda que em $93 \%$ dos contratos o fator de risco de força maior ou por caso fortuito foi partilhado entre o setor público e o setor privado. Dessa forma, a partilha dos riscos já se apresentaria individualmente como medida de mitigação desse risco, por força da Lei no 11.079/2004, para o setor privado. Nos 14 contratos onde se incluiu tal cláusula observase que se previu cláusula de seguro partilhada garantindo-se a mitigação; não se explicita a quem se aloca a cobertura da contratação de seguros. No caso de não se constituir a cobertura securitária, e por força da lei, intui-se que o setor público deve ensejar o mecanismo de reequilíbrio econômico-financeiro ou na pior das hipóteses encerrar o contrato, absorvendo assim todo o risco. 


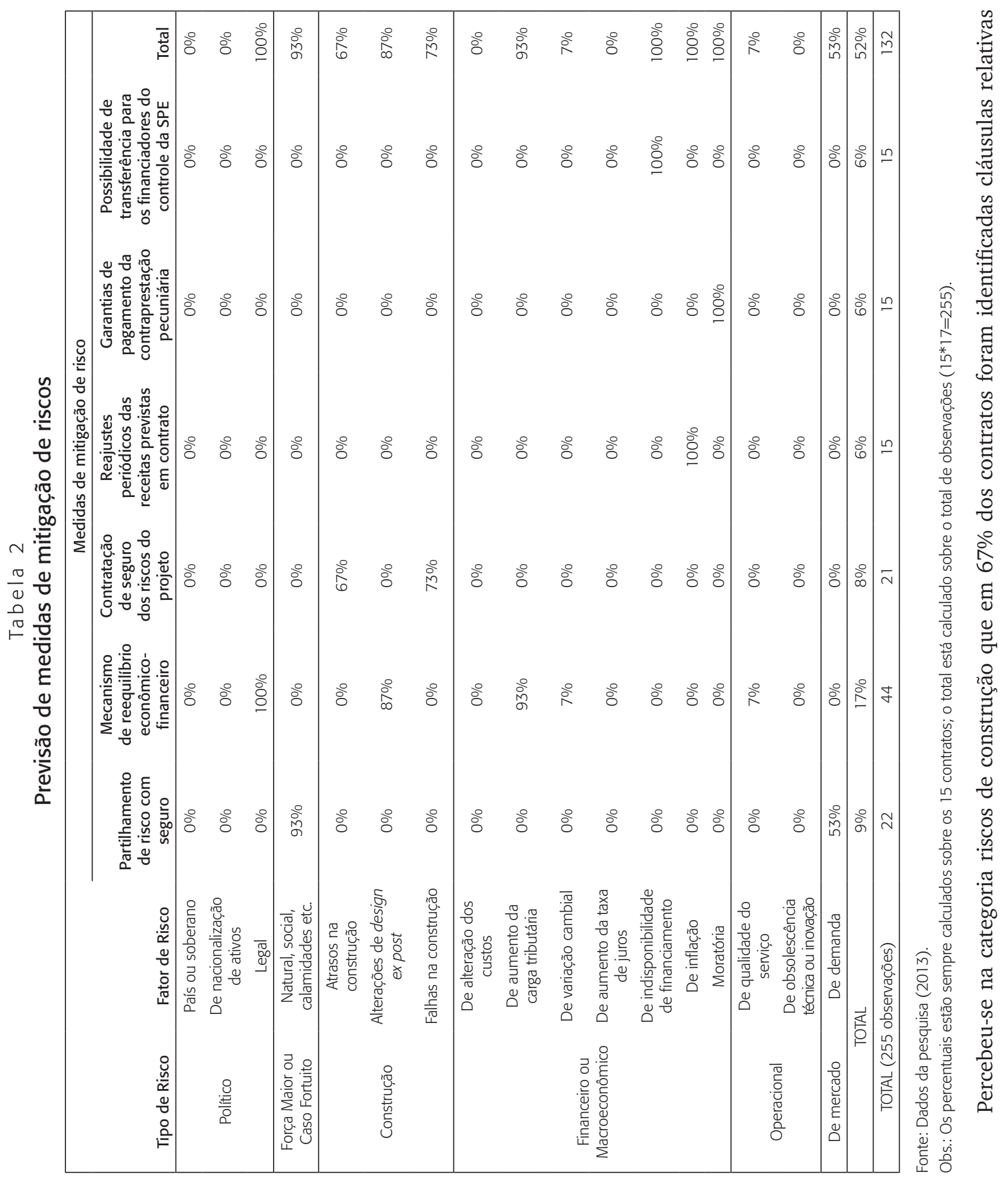


à contratação de seguro como medida de mitigação para o atraso da obra; já em 73\% dos contratos foram identificadas cláusulas relativas à contratação de seguro como medida de mitigação, para o caso de ocorrência de falhas na construção.

Em ambos os casos, vale destacar a intenção de transferir os riscos supracitados para terceiros mediante a contratação de seguro de obra civil em construção ou de seguro garantia. Essa iniciativa também gera custos adicionais — dos prêmios de seguros — sem que se identifiquem cláusulas que aloquem claramente tais custos.

Nos fatores de risco advindos de alterações de design ex post do projeto nota-se que em $87 \%$ dos contratos a forma de mitigação prevista é a repactuação contratual por meio do mecanismo de reequilíbrio econômico-financeiro. Nos contratos estudados, de forma recorrente, as modificações de escopo são entendidas como ingerência do Estado, dando assim ao setor privado a possibilidade de acionamento do trâmite necessário para o reequilíbrio econômicofinanceiro, protegendo-se assim o parceiro privado pela ocorrência de eventos dessa natureza.

Com relação à categoria de riscos financeiros decorrentes de variações nos custos, no câmbio e nas taxas de juros, observa-se que em 100\% dos contratos estudados não foram identificadas medidas de mitigação que evitem a exposição do setor privado a variações nesses dois fatores de risco. Vale destacar que a não identificação dessas medidas nos contratos e editais não determina que esses fatores de riscos não estejam sendo tratados pelo setor privado.

Instrumentos financeiros legais, tais como securitização e leasing que não fazem parte estrita do objeto deste estudo, são comumente utilizados nos planos de negócios, como medidas de mitigação para operações estruturadas junto aos credores. Apenas em 7\% dos contratos o ente público previu o mecanismo de reequilíbrio-econômico na ocorrência de variação superior a 50\% da taxa prevista para o câmbio. Dessa forma, o ente público obrigou-se a cobrir os impactos decorrentes dessa variação no serviço da dívida do parceiro privado.

Ainda na mesma categoria, para o risco de criação de impostos ou alterações nas alíquotas, percebe-se que o setor privado é impactado diretamente, já que o sucesso da consecução do seu fluxo de caixa depende das premissas (inclusive tributárias) descritas no plano de negócios.

Em 93\% dos contratos o parceiro público previu cláusulas onde o parceiro privado pode mitigar ocorrências destes eventos por intermédio do acionamento de medidas de reequilíbrio econômico-financeiro do contrato.

O risco de inflação, entendido neste trabalho como o risco de alteração nos preços reais, com impacto na variação de receita real e consequentemente na rentabilidade real, não foi alocado de forma objetiva (apesar do impacto no setor privado), mas foi mitigado em 100\% dos projetos avaliados por meio de cláusulas de reajuste anual de valores por índice previamente informado. Dessa forma, o impacto desse risco para o setor privado passou a ser mitigado pela previsão contratual de indexação das receitas do projeto. Exceção a esse aspecto foram os projetos associados a preços dependentes de livre demanda, como estádios de futebol.

Verificou-se, ainda, que o risco de não haver recursos próprios ou de terceiros para o empreendimento, culminando com o término antecipado da obra e com a possível perda de investimento de capital, vem sendo mitigado em $73 \%$ dos contratos avaliados pela possibili- 
dade de transferência para os financiadores do controle da sociedade de propósito específico (cláusula step in rigtht). Essa possibilidade vem sendo dada em garantia aos credores em detrimento das outras possibilidades de mitigação dos riscos (art. 5o, §2ํ da Lei no 11.079/2004) como forma de minimizar a aversão ao risco dos credores, facilitando assim a captação de recursos para projetos com essa complexidade. Em $27 \%$ dos contratos não foram localizadas cláusulas para mitigação desse fator de risco.

$\mathrm{Na}$ categoria riscos financeiros, percebe-se que o risco de as obrigações pecuniárias assumidas pelo parceiro público (situação de moratória) não serem cumpridas, apesar de não ser alocado de forma objetiva (apesar do impacto direto no setor privado), vem sendo mitigado nos contratos, mediante os recursos previstos no art. 8o da Lei ํㅜ 11.079/2004.

De fato, observa-se que $100 \%$ dos contratos avaliados explicitaram medidas que têm como objetivo afastar a possibilidade de o ente público não cumprir com os pagamentos previstos. Vale ainda destacar que nos contratos foram citadas várias formas de garantia, que permitem concluir que elas estão sendo utilizadas de forma complementar, como maneira a assegurar todo o valor dado pelo poder público por meio da contraprestação pecuniária.

$\mathrm{Na}$ categoria de risco operacional percebe-se que, apesar de sofrerem influência do parceiro público, à semelhança dos riscos de construção, os riscos de obsolescência técnica e de qualidade do serviço são intrínsecos ao empreendimento, onde por natureza o parceiro privado tem maior controle.

Ainda assim, como nos riscos de variações dos custos, do câmbio e dos juros, em $100 \%$ dos contratos não foram identificadas medidas de mitigação para o risco de qualidade do serviço.

Para o caso do risco de obsolescência técnica, em 93\% dos contratos, não foram identificadas medidas de mitigação desse fator de risco. Em apenas 7\% dos contratos com risco de obsolescência técnica foi prevista sua mitigação pela revisão do contrato. Nesse contrato, atualizações técnicas não previstas ensejam o mecanismo de reequilíbrio econômico-financeiro.

Também vale destacar que a não identificação dessas medidas nos contratos e editais não determina que esses fatores de riscos não estejam sendo tratados pelo setor privado. A expertise no segmento do projeto e a eficiência da empresa devem contribuir para a mitigação desses fatores de riscos.

Na categoria mercado o risco de demanda em 53\% dos contratos foi localizado e mitigado pelo partilhamento dos riscos com o setor público. Percebe-se que as cláusulas que tratam desse fator de risco fazem alusão não somente aos riscos negativos, onde em todos os casos o setor público enseja o reequilíbrio econômico-financeiro para recompor a demanda prevista no plano de negócio, mas também ao risco positivo quando a demanda prevista é superada e a receita é partilhada com o setor público. Observa-se que os gatilhos que disparam o reequilíbrio econômico-financeiro não seguem um padrão, variando de forma situacional, conforme o contrato. Em 47\% dos contratos esse fator de risco não foi localizado. 


\section{Conclusão}

A pesquisa teve como objetivo investigar o tratamento dado à identificação, alocação e adoção de medidas de mitigação de risco nos contratos de parceria público-privada celebrados com órgãos governamentais brasileiros para a concretização de obras de infraestrutura pública, no período de 2004 a 2010; consultaram-se 15 contratos de 22 celebrados no período.

Foram identificados 17 fatores de riscos textualmente tratados nos contratos, gerando assim 255 observações a serem objeto de alocação entre os parceiros privados e públicos, identificando-se ainda casos de alocação partilhada entre eles, além da inexistência de menção sobre a alocação de riscos identificados em 96 casos (38\%). O restante dos riscos identificados foi posto como responsabilidade do setor privado em $36 \%$ dos casos, sendo os demais de responsabilidade do setor governamental (17\%) ou partilhados (9\%).

Apesar de tal alocação, nos próprios contratos foram estabelecidas cláusulas prevendo medidas de mitigação dos efeitos de riscos que, efetivamente, se efetivem. Com relação a tais medidas catalogaram-se cinco classes de providências, quais sejam:

1) Mecanismo de reequilíbrio econômico-financeiro em $17 \%$ dos casos, atendendo a perdas oriundas de intervenção do setor público (alterações legais, alterações de design ex post e variações tributárias), o que implicaria, a nosso juízo, assunção de riscos adicionais, pela necessidade de renegociação no futuro, sem qualificações expressas nos contratos;

2) Repartição de riscos assumidos pelo parceiro privado, por contratação de seguro em $9 \%$ dos casos, condição voltada para fatos imprevisíveis ou de difícil previsão (força maior e demanda);

3) Contratação de seguros contra os riscos do projeto em $8 \%$ das observações, com custos inclusos no próprio contrato, referente a questões relacionadas com as obras civis;

4) Indexação dos contratos e garantias de pagamento da contraprestação pecuniária, relacionadas na Lei no $11.079 / 2004$, presente em $12 \%$ dos contratos, o que se traduziria em custos adicionais diretos para o erário;

5) Transferência de riscos para os financiadores (step in right), presente em 6\% dos contratos.

Enfim, a própria alocação objetiva dos fatores de riscos é medida de mitigação passível de adaptação nos contratos de concessões comuns, regidos pelas Leis oㅡ 8.666/1993 e noㅡ 8.987/1995.

Desse modo, é possível inferir que há evidências de que os parceiros privados arcam com baixa participação na assunção de riscos associados a obras de infraestrutura na modalidade de financiamento por meio de parcerias público-privadas, seja em face do arcabouço legal protetivo para ocorrências imprevistas, seja porque se garantem de antemão indexações nos preços ou tarifas, ou ainda porque se permite textualmente o mecanismo de reequilíbrio financeiro, sem definições claras sobre sua aplicação. 
Pode-se contrapor o caráter impreciso dos termos contratuais nos contratos no âmbito brasileiro com a experiência relatada por Thomson (2005), que estabelece com clareza os riscos cobertos contratualmente, e mesmo com pesquisa de Pérez (2011), que define percentuais certos para a assunção de risco pelas partes envolvidas.

A possibilidade de litígios fica patente nos termos de nossa tradição jurídica codificada, uma vez que a interpretação da maior parte das cláusulas examinadas não se baseia em legislação emitida, no que tange ao tema de alocação e mitigação de riscos. Essa seria, a propósito, avenida para estudos futuros, onde se examinassem tais contratos pela ótica eminentemente jurídica.

Por fim, outra via de pesquisas futuras sugerida é a de acompanhar por meio de estudo de caso a efetividade dos riscos e reponsabilidades contratadas nos projetos concluídos ou em andamento.

\section{Referências}

ALBUQUERQUE, Andrei A. de; REBELATTO, Daisy A.; SAVI, Érika M. de S. A parceria públicoprivada na infraestrutura econômica. Revista de Desenvolvimento Econômico - RDE, Salvador, n. 20, p. 76-89, jul. 2009.

AMARAL, Antônio C. C. Concessão de serviço público. 2. ed. São Paulo: Malheiros, 2002.

BARDIN, Laurence. Análise de conteúdo. São Paulo: Edições 70, 2011.

BORGES, Luiz F. X.; NEVES, Cesar das. Parceria público-privada: riscos e mitigação de riscos em operações estruturadas de infraestrutura. Revista do BNDES, v. 12, n. 23, p. 73-118, jun. 2005.

BRASIL Lei no 8.666, de 21 de junho de 1993, que regulamenta o art. 37, inciso XXI, da Constituição Federal, institui normas para licitações e contratos da Administração Pública e dá outras providências. Diário Oficial, Brasília, 22 jun. 1993.

BRASIL Lei no 8.987, de 13 de fevereiro de 1995, que dispõe sobre o regime de concessão e permissão da prestação de serviço público previsto no art. 175 da Constituição Federal, e dá outras providências. Diário Oficial, Brasília, 14 fev. 1995.

BRASIL. Lei n. 11.079, 30 de dez. 2005. Institui normas gerais para licitação e contratação de parceria público-privada no âmbito da administração pública. Brasília. Disponível em: < hwww.presidencia. gov.br/ccivil_03/_Ato2004-2006/2004/Lei/L11079.htm. >. Acesso em: 30 out. 2012.

COELHO, Antonio C.; MARTINS, Eliseu. Análise das demonstrações financeiras de bancos estatais brasileiros em face do postulado da entidade. Revista de Economia e Administração, v. 5, n. 1, p. 61-81, 2006.

FERREIRA, Pedro C. G.; MALLIAGROS, Thomas Georges. Investimentos, fontes de financiamento e evolução do setor de infraestrutura no Brasil: 1950-1996. Ensaios Econômicos, n. 346, 1999. 
FRANÇA, Maria A. de C. Repartição objetiva de riscos. Tese (doutorado em direito) — Faculdade de Direito, Universidade de São Paulo, São Paulo, 2011.

FRANCO, Viviane G. Parcerias público-privadas no Brasil: em busca de eficiência por meio da alocação de riscos. Dissertação (mestrado em economia política) — Pontifícia Universidade Católica de São Paulo, São Paulo, 2007.

GRIMSEY, Darrin; LEWIS, Mervyn K. Evaluating the risks of public private partnerships for infrastructure projects. International Journal of Project Management, v. 20, n. 2, p. 107-118, 2002.

HARB, Karina H. A revisão na concessão comum de serviço público. 5. ed. São Paulo: Malheiros, 2012.

LOUREIRO, Ana L. de C. Os contratos de PPP no direito brasileiro. Dissertação (mestrado em direito) — Universidade Candido Mendes, Rio de Janeiro, 2007.

MAIA, José N. B.; SARAIVA José F. S. A paradiplomacia financeira no Brasil da República Velha, 1890-1930. Revista Brasileira de Política Internacional, Brasília, v. 55, n. 1, p. 106-134, 2012.

MARTINS, Ana I. C. As parcerias público-privadas no setor das energias renováveis: o caso da energia eólica. Dissertação (mestrado em engenharia civil) - Instituto Superior Técnico, Universidade Técnica de Lisboa, Lisboa, 2008.

MATOS FILHO, José C.; OLIVEIRA, Carlos W. de A. O processo de privatização das empresas brasileiras. Ipea, n. 422, 1996.

NOBRE, Veimar C. de S. Metodologia para a seleção de projetos de parceria público-privada no setor de infraestrutura rodoviária no estado do Ceará. Dissertação (mestrado em engenharia de transportes) — Universidade Federal do Ceará, Fortaleza, 2006.

NUNES, Ricardo da C. Privatização e ajuste fiscal: a experiência brasileira. Planejamento e Políticas Públicas, Rio de Janeiro, n. 18, p. 171-213, 1998.

PAIVA, Sílvia M. C.; ROCHA, Carlos A. A. Parcerias público-privadas. O papel do Senado Federal na discussão e aprovação da Lei no 11.079, de 2004. Consultoria Legislativa do Senado Federal, n. 25, 2005.

PEGO FILHO, Bolívar; CÂNDIDO JÚNIOR, José O.; PEREIRA, Francisco. Investimento e financiamento da infraestrutura do Brasil: 1990/2002. Ipea, n. 680, 1999.

PENA, Fernando E. Das privatizações às parcerias público-privadas: o Brasil numa perspectiva comparada. Dissertação (mestrado em administração pública) - Escola de Governo Professor Paulo Neves de Carvalho, Fundação João Pinheiro, Belo Horizonte, 2008.

PÉREZ, Jaime Díaz. Retos de la colaboración público-privada para el desarrollo de infraestructuras públicas (PPP). Boletín Económico do ICE, n. 3012, p. 15-21, 2011.

PINHEIRO, Armando C. A experiência brasileira da privatização: o que vem a seguir? Ipea, n. 87, 2000. 
REIS, Artur F. dos. Investimento público e infraestrutura e privatizações. In: ENCONTRO NACIONAL DE ECONOMIA, 8., Salvador, 2008.

RICHARDSON, Roberto J. Pesquisa social: métodos e técnicas. 3. ed. rev. ampl. São Paulo: Atlas, 2008.

SILVA, Antônio C. R. Metodologia da pesquisa aplicada à contabilidade: orientações de estudos, monografias, dissertações e teses. São Paulo: Atlas, 2003.

THOMSON, Campbell. Public-private partnerships: prerequisites for prime performance. EIB Papers, v. 10, n. 2, p. 113-129, 2005.

TORRIJOS, Jesús G. La financiación de la colaboración público-privada: El Project Finance. Presupuesto y Gasto Público, n. 45, p. 175-185, 2006.

ZAMCHIM, Kleber L. Contratos de parceria público-privada: risco e incerteza. São Paulo: Quartier Latin, 2012.

Carlos Marcio Campos Lima fez mestrado profissional no Programa de Pós-graduação em Administração e Controladoria da Universidade Federal do Ceará (PPAC-UFC). Gerente do Escritório de Projetos — Tivit. E-mail: carlo_marci@hotmail.com.

Antonio Carlos Coelho tem pós-doutorado em ciências contábeis pela Universidade de São Paulo (USP). Professor associado ao Programa de Pós-graduação em Administração e Controladoria da Universidade Federal do Ceará (PPAC-UFC). E-mail: accoelho47@gmail.com. 
